\title{
Traumatic retroclival epidural hematoma in pediatric patient- Case report and review of literature
}

Muhammad Zubair Tahir

Aga Khan University, zubair.tahir@aku.edu

S. A. Quadri

Aga Khan University

Sonia Hanif

Aga Khan University

Gohar Javed

Aga Khan University, gohar.javed@aku.edu

Follow this and additional works at: https://ecommons.aku.edu/pakistan_fhs_mc_surg_neurosurg

Part of the Neurology Commons, Neurosurgery Commons, and the Surgery Commons

\section{Recommended Citation}

Tahir, M., Quadri, S., Hanif, S., Javed, G. (2011). Traumatic retroclival epidural hematoma in pediatric patient- Case report and review of literature. Surgical Neurology International, 2, 78.

Available at: https://ecommons.aku.edu/pakistan_fhs_mc_surg_neurosurg/37 


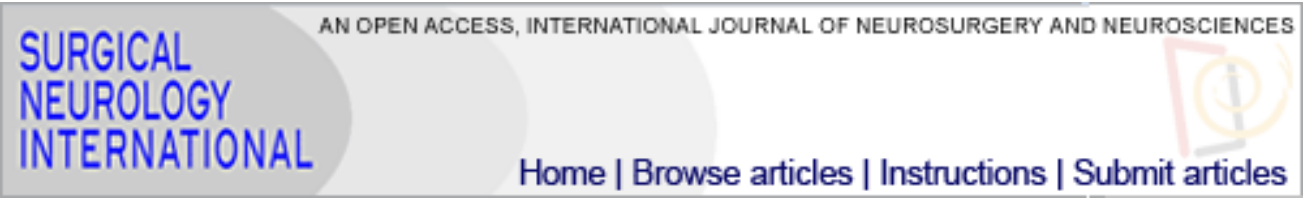

Surg Neurol Int. 2011; 2: 78.

PMCID: PMC3130360

Published online 2011 Jun 15. doi: 10.4103/2152-7806.82085

\section{Traumatic retroclival epidural hematoma in pediatric patient-Case report and review of literature}

Muhammad Zubair Tahir, ${ }^{*}$ S. A. Quadri, Sonia Hanif, and Gohar Javed

Department of Neurosurgery, Aga Khan University Hospital, Karachi, Pakistan

Muhammad Zubair Tahir: muhammad.zubair@aku.edu; S. A. Quadri: dr.saqader@gmail.com; Sonia Hanif: soniahanif@gmail.com; Gohar Javed: gohar.javed@aku.edu

*Corresponding author

Received 2011 Apr 15; Accepted 2011 May 25.

Copyright : ( 2011 Tahir MZ.

This is an open-access article distributed under the terms of the Creative Commons Attribution License, which permits unrestricted use, distribution, and reproduction in any medium, provided the original author and source are credited

This article has been cited by other articles in PMC.

Abstract

Go to:

Background:

Retroclival epidural hematoma (REDH) is a very rare entity in the practical field of neurosurgery. Only a few cases have been reported in literature. The authors present to you case of a 12-year-old female, a victim of road traffic accident (RTA), who had presented to us with loss of consciousness and seizures.

\section{Case Description:}

Magnetic resonance imaging revealed retroclival hematoma. She was managed on conservative grounds and discharged with assurance of multiple follow-up visits.

\section{Conclusion:}


Very few cases of REDH have been reported in pediatric population to date. It should be suspected in children with head and neck injuries who have been a victim of RTAs. Most likely underdiagnosed due to its rarity; therefore, MRI should be considered when the suspicion is high. Atlanto-occipital dislocation should always be kept under consideration in all cases, and therefore should be managed and monitored very cautiously. In this report, the authors also present concise review of the literature pertaining to the pathogenesis and management of this rare clinical entity which has a high likelihood to be encountered and underdiagnosed by neurosurgeons in Emergency Room.

Keywords: Clivus, posterior fossa hematoma, post-traumatic epidural hematoma, retroclival epidural hematoma INTRODUCTION Go to:

Retroclival epidural hematoma (REDH) is an infrequent diagnosis in the pediatric age group. Very few cases have been reported in literature. Most of the reported cases have been consequences of road traffic accidents (RTA). The majority of these have had a benign clinical outcome with only four reported mortalities. We report to you the very first in this country along with a concise review of the literature focusing on the cause for a relatively high incidence in pediatric age group, pathophysiology, optimal approach, and management of this very rare entity with a high probability to be encountered and underdiagnosed by neurosurgeons when dealing with children who have been involved in an RTA.

\section{CASE REPORT}

This 12-year-old female was hit by a speeding motor vehicle while crossing street. She was brought to the Emergency Room (ER) within 30 minutes of the incident. She had three episodes of vomiting and one episode of generalized seizures on arrival at ER. On clinical examination, she was vitally stable. Her Glasgow Coma Scale was assessed to be 11/15 (E4 V2 M5). The pupils were bilaterally reactive and equal. She had right-sided hemiparesis (Power 4/5). The rest of the examination was within normal confines. For seizures, she was administered a rapid acting benzodiazepine. Due to high risk of cervical spine injury, a cervical collar was placed. She was rapidly accommodated in special care unit.

Roentgenograms of her chest and pelvis did not show any abnormalities. Her cervical spine x-rays showed no fracture or dislocation. Computed tomography (CT) scans of the head revealed mild cerebral edema and epidural retroclival hematoma [ $\underline{\text { Figure 1] }}$. During the 10-day stay at the hospital, her conscious level gradually improved. On fifth day, she was fully alert and oriented.

\section{0}

Figure 1

Axial (a), Coronal (b), and Sagittal (c) CT brain showed retroclival EDH (Black arrows)

Magnetic resonance imaging (MRI) was done on the fifth day. It confirmed the presence of retroclival hematoma and tiny petechial hemorrhages on left half of Pons and right thalamus [iigure 2]. She was discharged on 10th post admission day with 
assurance of long-term follow-up visits. At the time of discharge, she had diplopia and persistent right hemiparesis.

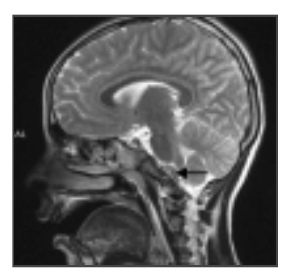

\section{Figure 2}

Sagittal T2-W MRI brain showing hypodense EDH hematoma behind the clivus (Arrow)

She returned to the out-patient clinic after a week of discharge. A marked improvement was seen in the general health and the right-sided weakness over subsequent visits.

REDH in the posterior fossa is a relatively recent entity, the first case being published in 1941.[ㄷ] It is an uncommon variant of all epidural hematomas and a subtype of posterior fossa epidural hematoma, estimated to comprise 1.2 to $12.9 \%$ of all epidural hematomas.[묘, $\underline{15}]$

REDH has been reported both in children and in adults. However, far more cases of traumatic REDH have been reported in pediatric age group with almost all the patients being a victim of a high-speed motor vehicle crash either as a pedestrian, bicyclist, or as a passenger in the vehicle. In contrast, cases of spontaneous retroclival hematoma are not infrequently reported in adults' age group. It has been described in adults in relation to thunderclap headache, $[\underline{5}, \underline{17}, \underline{19}]$ secondary to pituitary apoplexy,[] ] decompressive craniectomy in cerebellar infarction,[]] and in a patient taking oral anticoagulants.[]]

The high number of reported cases of traumatic REDH in children as compared with adults remains a matter of considerable controversy. Several theories have been proposed. Menezes has proposed the relative instability of the craniovertebral junction in children as one of the causes.[12] The craniovertebral junction is a complex comprising of several bones: occipital bone around foramen magnum, atlas and axis with the specialized ligamentous support.[11] The structure of the complex is shaped to provide mobility at the expense of stability.[12] In children, the axis of the joint is more horizontal. The orientation, along with relatively shallow lateral facet joints, incompletely developed bones of the complex, and increased elasticity of the ligaments accounts for increased mobility of the spine.[4] The craniovertebral junction is more susceptible to injuries in young children due to high pivot of neck motion. Therefore, hypermobility of the spine, at the fulcrum of neck motion, coupled with low inertia[19] of children, make them more prone to hyperflexion/hyperextension injuries than adults in a typical RTA; therefore, atlanto-occipital or atlantoaxial dislocations have also been reported.

The mechanism of formation of retroclival hematoma secondary to trauma has not been proven. Direct trauma may lead to skull base fracture or ligamentous disruption, the latter being more common in children due to ligamentous laxity. This, in turn, may lead to dural stripping, which is more prevalent in children.[16] Bleeding, that occurs from venous sinuses, is limited by the 
margins of the tectorial membrane.[13] In one of the cases published so far, an 11-year-old girl had diastasis of the sphenooccipital synchondroses that had probably contributed to the hematoma.[ㅁ] Initial CT scans may erroneously appear normal. Therefore, MRI is essential to delineate the finer anatomical details of the disease entity.[18]

Compared with epidural hematomas in the supratentorial compartment where there is more room for extension of masses, the posterior fossa epidural hematomas may have a grave prognosis due to the lack of expansible scope and presence of vital structures resulting in sudden deterioration.[2] In contrast, REDH in the posterior fossa demonstrates no mass effect and most of the REDH reported in the literature resolved spontaneously (in about 2 weeks). Therefore, they are managed conservatively with serial recordings of CT scans.

In all the reported cases of traumatic retroclival hematoma, the prognosis has remained excellent. Despite the four mortalities, all the patients have recovered well with no morbidities. One of the two patients with atlantoaxial dislocations had mild abducent nerve palsy, while the other suffered from quadriplegia. Surgery was required in only four cases, two with transoral

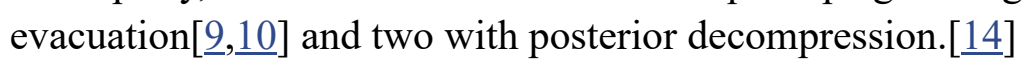

The two patients who had evacuation of hematoma by transoral route showed good outcome. Therefore, the best management option is the conservative one, with placement of cervical collar for stability, and regular observational follow-up visits.

\section{CONCLUSION}

Traumatic REDH is a rare entity, with greater prevalence in pediatric population. It should be suspected in children with head and neck injuries who have been a victim of RTA. REDH are most likely underdiagnosed; therefore, MRI should be considered when the suspicion is high. It has a benign outcome with a favorable prognosis, but atlanto-occipital dislocation should always be kept under consideration in all cases. Conservative management is the treatment of choice in the majority of cases.

Publication of this manuscript has been made possible by an educational grant from ELEKTA

Footnotes Go to:

Available FREE in open access from: $\underline{\text { http://www.surgicalneurologyint.com/text.asp?2011/2/1/78/82085 }}$

\section{REFERENCES}

1. Agrawal D, Cochrane DD. Traumatic retroclival epidural hematoma - A pediatric entity? Childs Nerv Syst. 2006;22:670-3. [PubMed]

2. Bozbuga M, Izgi N, Polat G, Gurel I. Posterior fossa epidural hematomas: observations on a series of 73 cases. Neurosurg Rev. 1999;22:34-40. [PubMed] 
3. Calli C, Katranci N, Guzelbag E, Alper H, Yunten N. Retroclival epidural hematoma secondary to decompressive craniectomy in cerebellar infarction: MR demonstration. J Neuroradiol. 1998;25:229-32. [ubMed]

4. Cirak B, Ziegfeld S, Knight VM, Chang D, Avellino AM, Paidas CN. Spinal injuries in children. J Pediatr Surg. 2004;39:60712. [PubMed]

5. Coleman CC, Thomson JL. Extradural Hematomas in Posterior Fossa. Surgery. 1941;10:985.

6. Goodman JM, Kuzma B, Britt P. Retroclival hematoma secondary to pituitary apoplexy. Surg Neurol. 1997;47:79-80. [PubMed]

7. Guilloton L, Godon P, Drouet A, Guerard S, Aczel F, Ribot C. [Retroclival hematoma in a patient taking oral anticoagulants] Rev Neurol (Paris) 2000;156:392-4. [PubMed]

8. Kurosu A, Amano K, Kubo O, Himuro H, Nagao T, Kobayashi N, et al. Clivus epidural hematoma. Case report. J Neurosurg. 1990;72:660-2. [PubMed]

9. Kwon TH, Joy H, Park YK, Chung HS. Traumatic retroclival epidural hematoma in a child: case report. Neurol Med Chir (Tokyo) 2008;48:347-50. [PubMed]

10. Marks SM, Paramaraswaren RN, Johnston RA. Transoral evacuation of a clivus extradural haematoma with good recovery: A case report. Br J Neurosurg. 1997;11:245-7. [ubMed]

11. Menezes AH. Craniovertebral junction database analysis: incidence, classification, presentation, and treatment algorithms. Childs Nerv Syst. 2008;24:1101-8. [PubMed]

12. Menezes AH. Developmental abnormalities of the craniovertebral junction. In: HR W, editor. Youman's neurological surgery. 5 ed. Philadelphia: WB Saunders; 2003. pp. 3331-46.

13. Mizushima H, Kobayashi N, Sawabe Y, Hanakawa K, Jinbo H, Iida M, et al. Epidural hematoma of the clivus. Case report. J Neurosurg. 1998;88:590-3. [․ubMed]

14. Papadopoulos SM, Dickman CA, Sonntag VK, Rekate HL, Spetzler RF. Traumatic atlantooccipital dislocation with survival. Neurosurgery. 1991;28:574-9. [PubMed]

15. Ratilal B, Castanho P, Vara Luiz C, Antunes JO. Traumatic clivus epidural hematoma: case report and review of the literature. Surg Neurol. 2006;66:200-2. discussion 202. [PubMed]

16. Robertson JH, Clark WC, Acker JD. Bilateral occipital epidural hematomas. Surg Neurol. 1982;17:468-72. [PubMed] 
17. Schievink WI, Thompson RC, Loh CT, Maya MM. Spontaneous retroclival hematoma presenting as a thunderclap headache. Case report. J Neurosurg. 2001;95:522-4. [PubMed]

18. Tubbs RS, Griessenauer CJ, Hankinson T, Rozzelle C, Wellons JC, 3rd, Blount JP, et al. Retroclival epidural hematomas: A clinical series. Neurosurgery. 2010;67:404-6. discussion 406-407. [릴ed]

19. Williams PL, Dyson M. Gray's Anatomy. 37th ed. New York: Churchill Livingstone; 1992. Osteology, Intracartilaginous ossification; pp. 304-8.

Articles from Surgical Neurology International are provided here courtesy of Wolters Kluwer -- Medknow Publications 